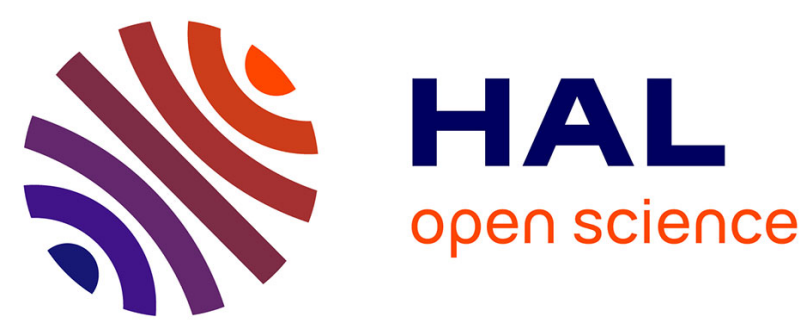

\title{
Sound absorption of a new bionic multi-layer absorber
} Yonghua Wang, Chengchun Zhang, Luquan Ren, Mohamed Ichchou,

Marie-Annick Galland, Olivier Bareille

\section{To cite this version:}

Yonghua Wang, Chengchun Zhang, Luquan Ren, Mohamed Ichchou, Marie-Annick Galland, et al.. Sound absorption of a new bionic multi-layer absorber. Composite Structures, 2014, 108, pp.400-408. 10.1016/j.compstruct.2013.09.029 . hal-01136642

\section{HAL Id: hal-01136642 \\ https://hal.science/hal-01136642}

Submitted on 5 Mar 2021

HAL is a multi-disciplinary open access archive for the deposit and dissemination of scientific research documents, whether they are published or not. The documents may come from teaching and research institutions in France or abroad, or from public or private research centers.
L'archive ouverte pluridisciplinaire HAL, est destinée au dépôt et à la diffusion de documents scientifiques de niveau recherche, publiés ou non, émanant des établissements d'enseignement et de recherche français ou étrangers, des laboratoires publics ou privés. 


\title{
Sound absorption of a new bionic multi-layer absorber
}

\author{
Yonghua Wang a,b,c, Chengchun Zhang a,*, Luquan Ren ${ }^{\mathrm{a}}$, Mohamed Ichchou ${ }^{\mathrm{b}}$, \\ Marie-Annick Galland ${ }^{\mathrm{c}}$, Olivier Bareille ${ }^{\mathrm{b}}$ \\ ${ }^{a}$ Key Laboratory of Bionic Engineering (Ministry of Education), Jilin University, Changchun 130022, PR China \\ ${ }^{\mathrm{b}}$ Laboratoire de Tribologie et Dynamique des Systèmes (LTDS), Ecole Centrale de Lyon, 69134 Ecully Cedex, France

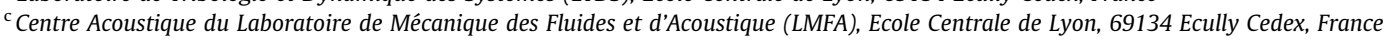

The interest of this article lies in the proposition of using bionic method to develop a new sound absorber. Inspired by the coupling absorption structure of a typical silent flying bird-owl, a bionic multi-layer structure is developed, which is composed of micro-silt plate, porous fibrous material and flexible micro-perforated membrane backed with airspace. The impedance transfer method and finite element simulation method (ACTRAN) are applied to calculate the acoustic performance and analyze the influence of different parameters of each layer on absorption coefficients of this model. The effectiveness of this proposed model is tested based on numerical simulations. The average normal incidence absorption coef-ficient reaches 0.85 within the frequency range from 200 to $2000 \mathrm{~Hz}$. The significant improvement of absorption coefficients can be mainly due to the Helmholtz effects of micro-silt plate and flexible micro-perforated membrane, and the combination with porous materials lead to even better absorption performance in broadband.

\section{Introduction}

In recent years, noise control has attracted much attention for improving living environments. Multi-layer acoustic absorbers composed of perforated plates, airspaces and porous materials are commonly applied to absorb broadband noise. However, the acoustic absorption of these multi-layer acoustic absorbers is mainly dependent on their fabrication. In this paper, a new absorption structure is developed through biomimetic method, and the factors that have significant influence on the acoustic absorption performance are analyzed.

Biology has perfected its designs and formed many fruitful abilities through evolution of billions of years. Efficient and reliable technologies and achievements can be developed by adopting the features of natural creations [1-5]. The owl, as observed today, has passed through series of evolution for over 12 million years. It is suggested that the owl has developed its strategy of a silent predator based on various characteristics of its body surface. At present, in the field of bionics, investigations on the noise reduction characteristics of owl body surface are mainly focused on its morphological features. Through comparative experiments on morphological characteristics of owl's wing surface, Graham [6] revealed that its special wing feathers had a significant impact on noise reduction capacity. Based on pneumatic noise test during

\footnotetext{
* Corresponding author.

E-mail address: jluzcc@jlu.edu.cn (C. Zhang).
}

the predation process of striped owl, Kroeger et al. [7] found that the primary feather edge was indented, which was conducive to noise suppression and even influenced its physical trajectory. Through long-term observation and experiments, Lilley [8] proposed following tentative but plausible reasons for the reduction and suppression of noise: (1) leading edge of primary feathers in the form of a comb, (2) trailing edge feathers in the form of a fringe, and (3) fluffy down on the wings, abdomen, legs and tarsus. On this basis, Lilley [9] attempted to optimize the take-off and landing of quiet commercial passenger transport according to the noise reduction characteristics of owl body surface and obtained satisfactory results. Ren et al. [10] and Liu et al. [11] in our group considered that the skin and feather of owl chest and abdominal may also play an important role on its silent flight. It was concluded that the noise suppression of the owl chest and abdominal was due to the synergy effect of material, skin structure and feather shape, etc., and further named as biological coupling. Inspired by this fact, a bionic coupling multi-layer structure is established in this article according to the bionic analogy principle.

The Smart Trim Technology Laboratory at the University of Delaware has developed an acoustic boundary control concept for active control to suppress interior sound radiation in helicopters, fixed-wing aircraft and land vehicles [12-15]. Hirsch et al. [16] presented the acoustic boundary control method and proposed a mathematical model of curved composite trim panels with impedance method. Davern [17] presented an experimental study on a three-layer assembly which contained perforated plate, porous 
material and airspace. Dunnand and Davern [18] proposed an analytical analysis for the flat-walled anechoic lining composed of outer, middle and inner layer porous materials. Jinkyo et al. [19] further studied the assembly with two layers of perforated plates backed with airspaces using equivalent electrical circuit method (EECM). Chen et al. [20] applied finite element method (FEM) to analyze the acoustic absorption of porous materials with different surface shapes and perforated plates. Buitrago et al. [21] gave a simulation analysis of Sandwich panels with carbon/epoxy skins and an aluminium honeycomb core by implement the model in ABAQUS/Explicit. Koutsawa et al. [22] presented a multi-scale model of viscoelastic constrained layer damping treatments for vibrating plates/beams and analyzed the sound transmission loss of the sandwich structure by the use of a sound transmission model. Wang et al. [23] presented a theoretical study on the sound transmission loss characteristics of unbounded orthotropic sandwich panels considering the transverse shear deformation. Larbi et al. [24] presented the theoretical formulation and the finite element implementation of vibroacoustic problems with piezoelectric composite structures connected to electric shunt circuits. Lin et al. [25] provided a detailed investigation of the impact of porous materials with different thickness and configuration on the perforated plate. Lee and Kwon [26] estimated the absorption performance of multiple layer perforated plate systems by transfer matrix method (TMM). Lee and Chen [27] proposed acoustic transmission analysis method to analyze the absorption of multi-layer absorber, which was subsequently developed into the impedance transfer method (ITM). Zhao et al. [28] compared EECM, ITM and TMM, and proved that ITM and TMM were essentially the same and more accurate than EECM. Recently, a variety of acoustic simulation software based on FEM are developed to be more convenient and visualized to investigate the various acoustic performance of absorption structure. Accordingly, ITM and FEM with ACTRAN are selected among all the methods for the acoustic analyses in this study.

\section{Materials and methods}

\subsection{Establishment of the bionic model}

Ren et al. [10] investigated the acoustic performance of the chest and abdominal skin and feather samples of long-eared owl, pheasant and pigeon. Some bionic characteristics of long-eared owl (a. ribbed structure of feather surface, b. micro-slit structure of feather, c. fibrous structure of fluff, d. cavity under the dermal layer of skin) and absorption comparison of different bird samples (e) are displayed in Fig. 1.

Fig. 1e indicates that the absorption coefficients of owl skin and overlying feathers are much higher than the other two birds, especially within the frequency range from $1000 \mathrm{~Hz}$ to $4000 \mathrm{~Hz}$. In the present study, bionic coupling modeling method is used to analyze the surface noise reduction mechanism based on the absorption characteristics of long-eared owl. The bionic analogies are characterized as follows: (1) The covering feather is analogous to rigid micro-slit plate, (2) The chest fluff is analogous to uniform fiber absorption material, (3) The dermis layer and subcutaneous cavity are analogous to a sound absorber, which compose of flexible micro-perforated membrane and airspace. The bionic coupling structure (a) and some comparative models (b) are shown in Fig. 2. Fig. 2b is composed of model 1 (a micro-slit plate backed with airspace), model 2 (a micro-slit plate backed with porous material), model 3 (double layer structure of micro-slit plate and micro-perforated membrane), model 4 (multi-layer structure of micro-slit plate, porous material and airspace) and model 5 (multi-layer structure of micro-slit plate, porous material, microperforated membrane and airspace). The first four are contrast models and the fifth is the bionic model.

\subsection{Calculation method of acoustic performance}

The methods used to analyze the various absorption performances in the study are discussed in following sections.

\subsubsection{Acoustic impedance of rigid micro-silt plate}

The calculation of acoustic performance of micro-slit plate is based on Maa's micro-silt theory [29] and expresses in the following equations:

$$
\begin{aligned}
& Z_{p}=\rho_{0} c_{0}(r+j \omega m)=\frac{12 \eta t}{p \rho_{0} c_{0}}\left(1+\frac{x^{2}}{18}\right)^{0.5}+\frac{j \omega t}{p c_{0}}\left[1+\left(25+2 x^{2}\right)^{-0.5}\right] \\
& Z_{D}=-j \rho_{0} c_{0} \cdot \cot \left(\frac{\omega D}{c_{0}}\right) \\
& Z=Z_{p}+Z_{D}
\end{aligned}
$$

where $\omega=2 \pi f, f$ is the frequency, $x=0.5 d \sqrt{\omega / \mu}$ is the perforated constant, $j=\sqrt{-1}, t, d, p$ are the thickness, width of micro-slit and porosity of micro-slit plate, respectively. $\eta, \rho_{0}, c_{0}$ are the kinematic viscosity of air, density of air and sound speed, $D$ is the thickness of the airspace behind the micro-slit plate, $Z_{P}, Z_{D}$ and $Z$ are the impedances of micro-slit plate, airspace and micro-slit absorber.

In the case of oblique incidence, when a sound wave is incident at an angle $\theta$ to the normal, the relative acoustic impedance of the cavity with thickness of $D$ becomes $\frac{1}{j \cos \theta} \cot \left(\frac{\omega D \cos \theta}{c_{0}}\right)$. If the incident direction of sound wave is vertical with the length direction of micro-slit, the normalized specific acoustic impedance is thus as Eq. (4). If it is parallel with the length direction of micro-slit, the normalized specific acoustic impedance is thus as Eq. (5):

$$
\begin{aligned}
& Z_{\theta}=r \cos \theta+j \omega m \cos \theta-j \cot \left(\frac{\omega D \cos \theta}{c_{0}}\right) \\
& Z_{\theta}=r+j \omega m-j \cot \left(\frac{\omega D \cos \theta}{c_{0}}\right)
\end{aligned}
$$

\subsubsection{Acoustic impedance of porous material}

Considering the accuracy and simplicity, Delany-Bazley-Miki [30] model is proposed to evaluate the wavenumber $k$ and characteristic impedance $Z_{c}$ :

$$
\begin{aligned}
& Z_{c}=\rho_{0} c_{0}\left[1+5.50\left(10^{3} \frac{f}{\sigma}\right)^{-0.632}-j 8.43\left(10^{3} \frac{f}{\sigma}\right)^{-0.632}\right] \\
& k=\frac{\omega}{c_{0}}\left[1+7.81\left(10^{3} \frac{f}{\sigma}\right)^{-0.618}-j 11.41\left(10^{3} \frac{f}{\sigma}\right)^{-0.618}\right]
\end{aligned}
$$

For $0.01<\frac{f}{\sigma}<1.00$

where $\sigma$ is the resistivity of porous material.

\subsubsection{Acoustic impedance of micro-perforated membrane}

A micro-perforated membrane backed by airspace makes a resonant system, which can be obtained using the impedance type of electro-acoustic analogy. Basically, the resonant system contains the mass-resistance element in series with the cavity reactance of the airspace [31]. The acoustic performance can be represented by the following equations: 

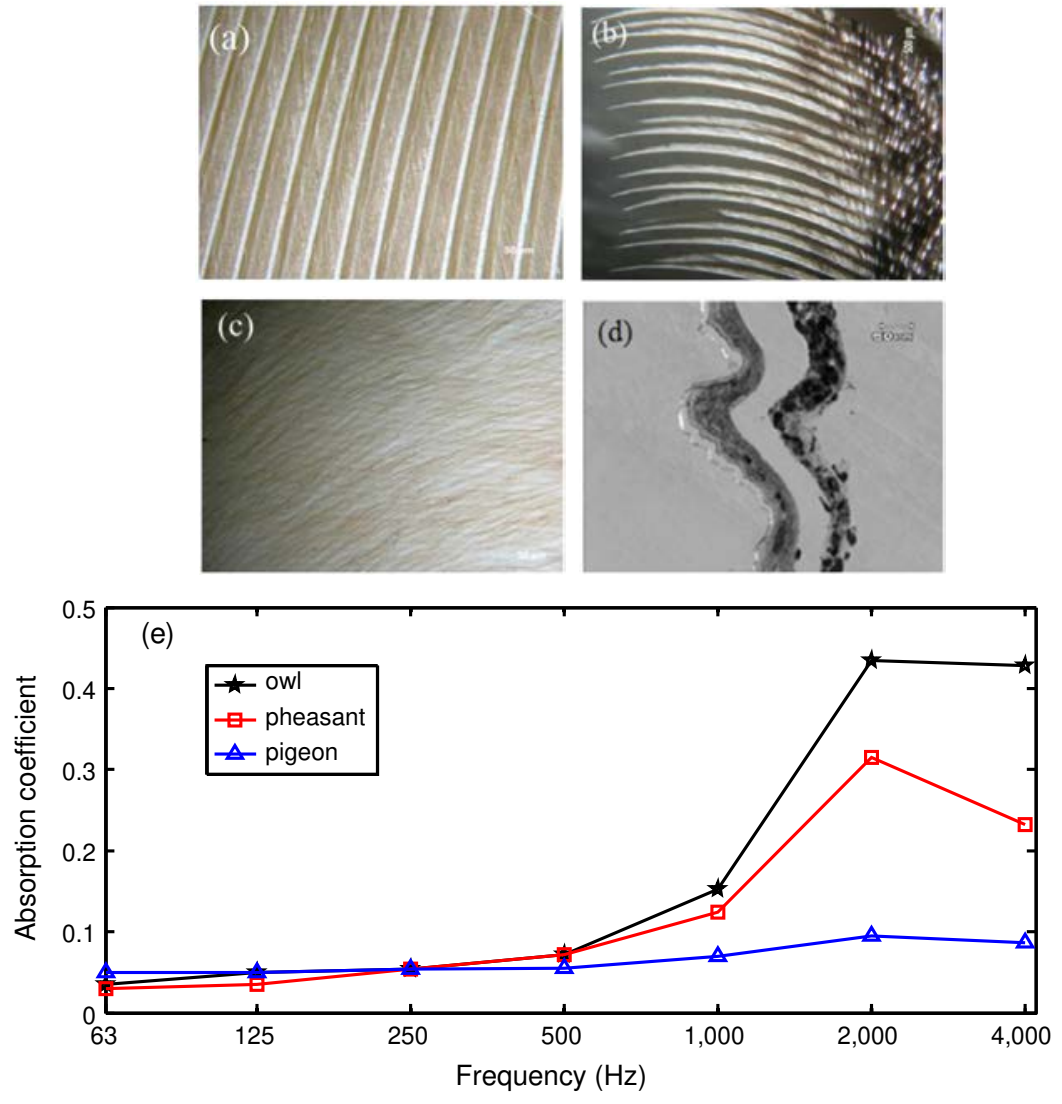

Fig. 1. Some bionic characteristics of long-eared owl and absorption comparison of different bird samples (Ren et al. [10]).

(a)

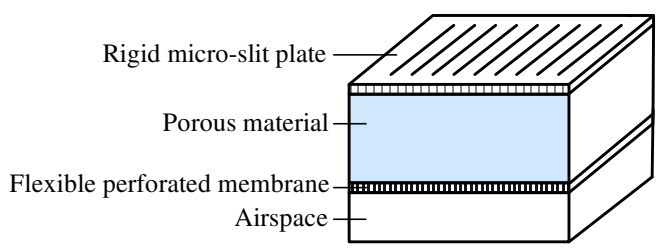

$Z_{M}=R_{M}+j M_{M}=\rho_{0} c_{0}\left(r^{\prime}+j \omega m^{\prime \prime}\right)$

$Z_{L}=R_{L}+j M_{L}=\rho_{0} c_{0}(r+j \omega m)$

$r=\frac{g_{1} t}{p d^{2}}\left[\left(1+\frac{x^{2}}{32}\right)^{0.5}+\frac{\sqrt{2} x}{8} \cdot \frac{d}{t}\right]$

$m=\frac{t}{p c_{0}}\left[1+\left(9+\frac{x^{2}}{2}\right)^{-0.5}+0.85 \frac{d}{t}\right]$

$Z=Z_{P}+Z_{D}=\frac{Z_{M} Z_{L}}{Z_{M}+Z_{L}}+Z_{D}=\rho_{0} c_{0}\left(H_{r}+j H_{m}-j \cot \left(\frac{\omega D}{c_{0}}\right)\right)$

With (b)
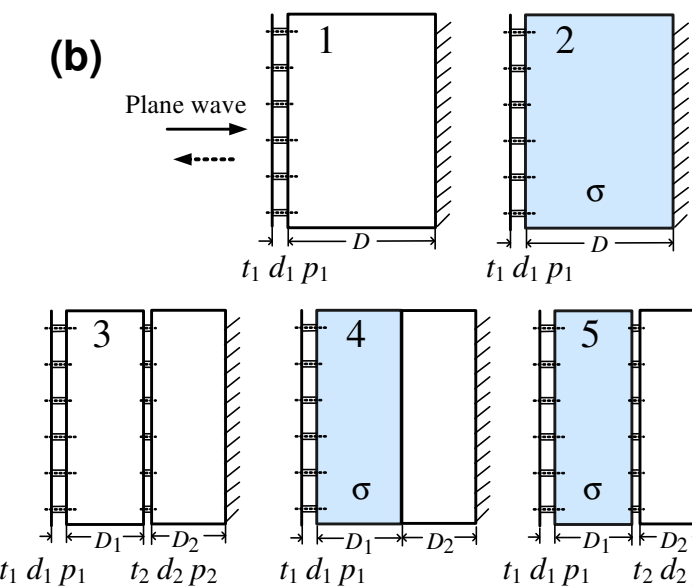

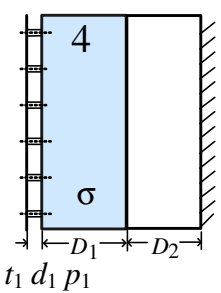

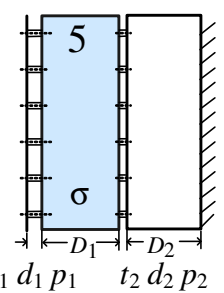

Fig. 2. Bionic absorption structure and comparative models.

$$
\begin{aligned}
& H_{r}=\frac{\left(r r^{\prime}-\omega^{2} m m^{\prime \prime}\right) \times\left(r+r^{\prime}\right)+\left(r^{\prime} \omega m-r m m^{\prime \prime}\right) \times\left[\omega\left(m+m^{\prime \prime}\right)\right]}{\left(r+r^{\prime}\right)^{2}+\left[\omega\left(m+m^{\prime \prime}\right)\right]^{2}} \\
& H_{m}=\frac{\left(r^{\prime} \omega m-r m m^{\prime \prime}\right) \times\left(r+r^{\prime}\right)+\left(r r^{\prime}-\omega^{2} m m^{\prime \prime}\right) \times\left[\omega\left(m+m^{\prime \prime}\right)\right]}{\left(r+r^{\prime}\right)^{2}+\left[\omega\left(m+m^{\prime \prime}\right)\right]^{2}}
\end{aligned}
$$

where $R_{M}$ and $M_{M}$ are the specific acoustic resistance and reactance of the membrane, $R_{L}$ and $M_{L}$ are the specific acoustic resistance and reactance of the apertures, $x=g_{2} d \sqrt{f}$ is the perforated constant, $m^{\prime}$ is the surface density of the membrane $\left(\mathrm{kg} / \mathrm{m}^{2}\right), m^{\prime \prime}=m^{\prime} \mid \rho_{0} c_{0}$ is the surface density of the membrane $\left(\mathrm{kg} / \mathrm{m}^{2}\right), r^{\prime}$ is the normalized specific acoustic resistance of the membrane, which mainly depends on 
mounting conditions. For a non-metallic material, $g_{1}=0.147$ and $g_{2}=0.316$. For a metallic material, $g_{1}=0.335$ and $g_{2}=0.21$.

The above sections are all for normal incidence of sound on the MPP absorber. In the case of oblique incidence, the MPP itself, as a locally reacting material, has its acoustic impedance $H_{r}+j \omega H_{m}$ unchanged. But in the cavity behind the panel, sound travels in direction $\theta$ to the normal, the same as the angle of incidence in the field, and the incident and reflected waves in the cavity have path difference $2 D \cos \theta$ instead of $2 D$ for normal incidence. Thus the relative acoustic impedance of the cavity becomes $\frac{1}{j \cos \theta} \cot \left(\frac{\omega D \cos \theta}{c_{0}}\right)$. The relative acoustic impedance on a unit area of the panel surface for oblique-incident wave is thus:

$Z_{\theta}=H_{r} \cos \theta+j\left(H_{m} \cos \theta-\cot \frac{\omega D \cos \theta}{c}\right)$

\subsubsection{Acoustic performance of multi-layer structure with ITM}

The generalization of ITM [27] for a multi-layer structure is shown in Fig. 3. In case of the first compartment of the multi-layer structure, surface acoustic impedance $\Gamma_{j 1}$ of the first layer (airspace or porous material) can be represented by the following equation:

$\Gamma_{j 1}=Z_{c j 1} \frac{-j Z_{r} \cot \left(k_{j 1} t_{j 1}\right)+Z_{c j 1}}{Z_{r}-j Z_{c j 1} \cot \left(k_{j 1} t_{j 1}\right)}$

where $Z_{r}$ is the back surface acoustic impedance of the first compartment, and it is backed with a rigid wall and taken as $\infty$, $Z_{c j 1}$ is the characteristic impedance of the layer considered for airspace or porous material. Similarly, the surface acoustic impedance of the next layer of airspaces or porous materials can also be evaluated by Eq. (17). However, the back surface acoustic impedance $Z_{r}$ is substituted by the surface acoustic impedance $\Gamma_{j 1}$ for the subsequent layer. Thus, the effects of various combinations of airspaces and porous materials between adjacent perforated plates can be accurately described.

The surface acoustic impedance $\Gamma_{c 1}$ for the first compartment can be evaluated by the surface acoustic impedance of the first layer of perforated plate $Z_{P 1}$ and the $k-1$ layer of airspace or porous material $\Gamma_{j(k-1)}$ as the following equation:

$\Gamma_{c 1}=Z_{p 1}+\Gamma_{j(k-1)}$

In case of the subsequent calculation, the surface acoustic impedance $\Gamma_{c 1}$ for the first compartment can be treated as the back surface acoustic impedance of the first layer of the second compartment. Consequently, the resultant surface acoustic impedance $\Gamma_{r}$ of the practical multi-layer acoustic absorber can be evaluated by ITM.

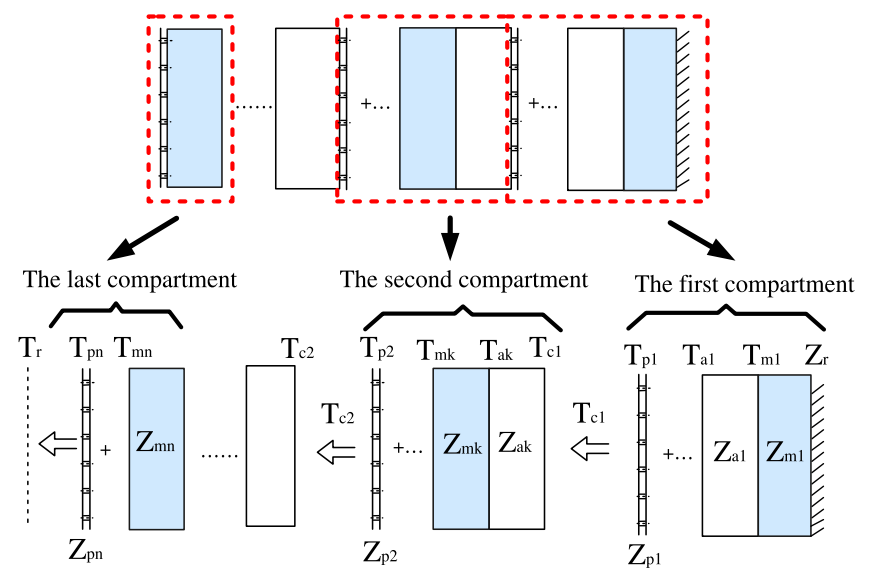

Fig. 3. Generalization of ITM for a multi-layer structure.
The absorption coefficients $\alpha$ of the multi-layer structure can be calculated by the following equation:

$\alpha=\frac{4 \operatorname{Re}\left(\Gamma_{r} / Z_{0}\right)}{\left[1+\operatorname{Re}\left(\Gamma_{r} / Z_{0}\right)\right]^{2}+\left[\operatorname{Im}\left(\Gamma_{r} / Z_{0}\right)\right]^{2}}$

where $Z_{0}=\rho_{0} c_{0}$ is the characteristic impedance of air, $\Gamma_{r}$ is the total acoustic impedance of the multi-layer absorber.

When a plane sound wave propagates in direction $\theta$ to the normal into the multi-layer structure, Eq. (17) can be rewritten to Eq. (20) [32]:

$\Gamma_{j 1}=\frac{Z_{c j 1}}{\cos (\theta)} \frac{-j Z_{r} \cos (\theta) \cot \left(k_{j 1} \cos (\theta) t_{j 1}\right)+Z_{c j 1}}{Z_{r} \cos (\theta)-j Z_{c j 1} \cot \left(k_{j 1} \cos (\theta) t_{j 1}\right)}$

In a diffuse sound field, the angle-averaged absorption coefficient can be calculated by the following equations:

$\alpha_{s}=\int_{0}^{\frac{\pi}{2}} \alpha_{\theta} \sin 2 \theta d \theta$

With

$$
\begin{aligned}
\alpha_{\theta} & =1-\left|\frac{\Gamma_{r} \cos \theta-1}{\Gamma_{r} \cos \theta+1}\right|^{2} \\
& =\frac{4 \operatorname{Re}\left(\Gamma_{r} / Z_{0}\right) \cos \theta}{\left[1+\operatorname{Re}\left(\Gamma_{r} / Z_{0}\right) \cos \theta\right]^{2}+\left[\operatorname{Im}\left(\Gamma_{r} / Z_{0}\right) \cos \theta\right]^{2}}
\end{aligned}
$$

\subsubsection{Acoustic performance with FEM (ACTRAN)}

Acoustic finite element software ACTRAN is also used to analyze the acoustic performance of the models based on ISO 10534$2: 1998$ (E) [33] by transfer function method. The specific procedure is as follows: Initially, the acoustic impedance and admittance of the micro-silt plate and perforated membrane are calculated by the above methods. Then, the finite element model is established according to the schematic diagram with reference to impedance tube of B\&K 4206 (Fig. 4a) and meshed in HYPERMESH (Fig. 4b). The acoustic calculations of the models were carried out on an acoustic mesh with approximately 30,000 grid points. The sizes of the meshes at the parts of impedance tube and absorber are $20 \mathrm{~mm}$ and $5 \mathrm{~mm}$, respectively. The diameter of the tube is $100 \mathrm{~mm}$ and the frequency band is $0-1600 \mathrm{~Hz}$. Finally, the finite element model is imported into ACTRAN and the boundary conditions and acoustic parameters are set. Especially for the micro-slit plate and micro-perforated membrane, an interface is created to connect the two sound space regions and transfer the acoustic admittance by assigning the admittance values to the coupling surfaces at the interface.

\section{Results and discussion}

\subsection{Validation of the results}

The comparisons of absorption coefficients of micro-perforated membranes (a, membrane 1 and experiment 1 are normal incident absorption coefficients, membrane 2 and experiment 2 are diffuse field absorption coefficients), double layer micro-perforated plate (b-model 3) and multi-layer acoustic absorbers (c-model 4) are shown in Fig. 5. The parameters of membrane 1 are: $m^{\prime}=0.19 \mathrm{~kg} / \mathrm{m}^{2}, t=0.17 \mathrm{~mm}, l=0.06 \mathrm{~mm}, p=0.83 \%$, membrane 2 with $m^{\prime}=0.14 \mathrm{~kg} / \mathrm{m}^{2}, t=0.11 \mathrm{~mm}, l=0.2 \mathrm{~mm}, p=0.79 \%$, model 3 with $d_{1}=d_{2}=0.8 \mathrm{~mm}, t_{1}=t_{2}=0.8 \mathrm{~mm}, p_{1}=p_{2}=3 \%, D_{1}=32 \mathrm{~mm}$, $D_{2}=23 \mathrm{~mm}$ and model 4 with $t_{1}=6.3 \mathrm{~mm}, p_{1}=4.7 \%, D_{1}=D_{2}=$ $25 \mathrm{~mm}$. The experiment data of micro-perforated membranes and model 4 are provided by Kang and Fuch [31] and Davern [17], respectively. It can be observed that the calculation results agree reasonably well with the experimental data for all the structures and the 

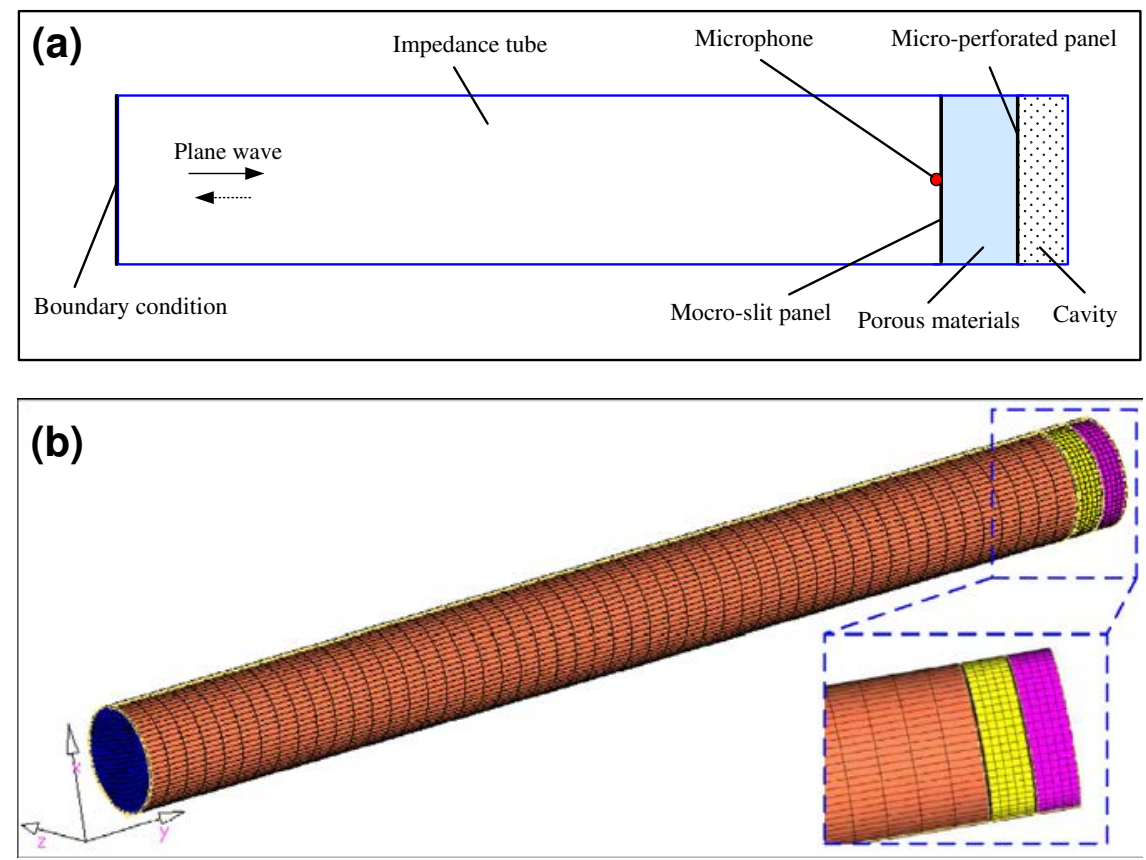

Fig. 4. Schematic diagram of FEM (a) and grid distribution (b) of bionic model.
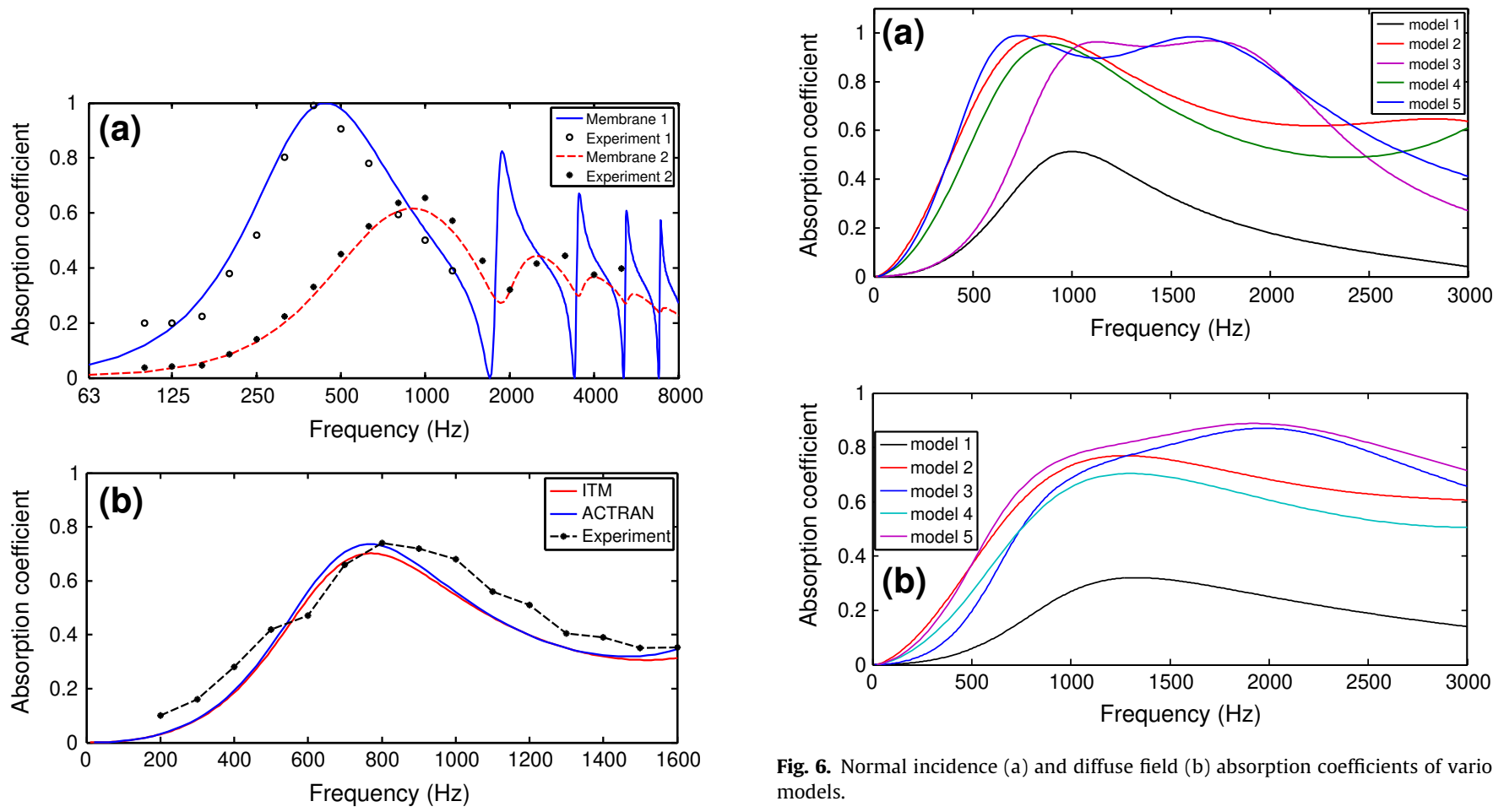

Fig. 6. Normal incidence (a) and diffuse field (b) absorption coefficients of various models.
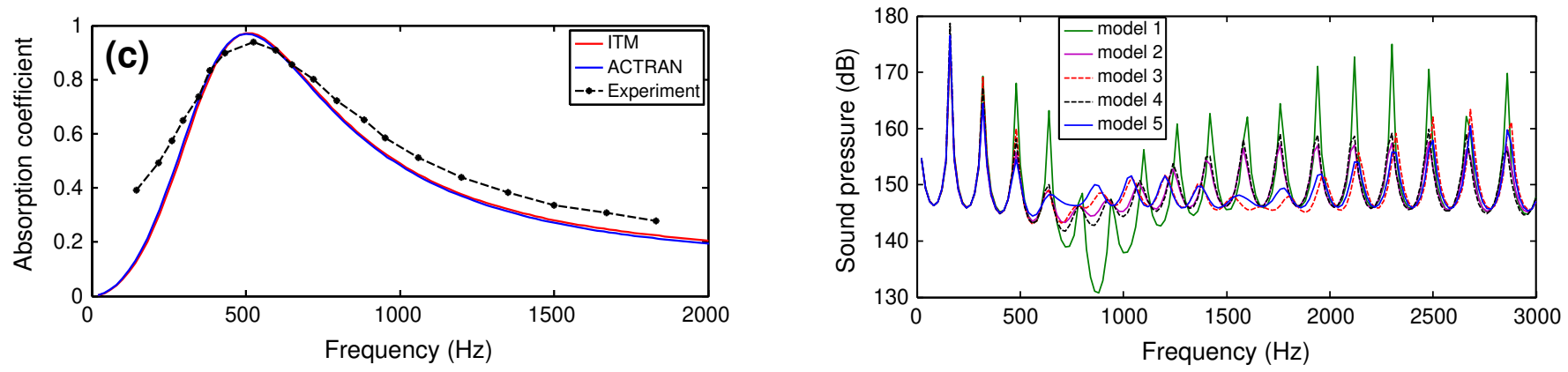

Fig. 5. Absorption coefficients of different structures.

Fig. 7. Surface sound pressure $(\mathrm{dB})$ of the various models. 
results of ITM and ACTRAN are almost the same. Thus, the methods described in the above section are validated for the study of acoustic characteristics of the models.

\subsection{Acoustic performance of the bionic model}

The parameters of the bionic model are determined according to the size of bionic characteristics of long-eared owl. With reference to Fig. 2b, the various parameters considered are: $t_{1}=2 \mathrm{~mm}, d_{1}=0.5 \mathrm{~mm}, \quad p_{1}=5 \%, t_{2}=0.2 \mathrm{~mm}, d_{2}=0.06 \mathrm{~mm}$, $p_{2}=0.83 \%, m^{\prime}=0.19 \mathrm{~kg} / \mathrm{m}^{2}, D_{1}=25 \mathrm{~mm}, \sigma=10,000 \mathrm{~Pa} \mathrm{~s} / \mathrm{m}, D_{2}=$ $25 \mathrm{~mm}$ and $D=D_{1}+D_{2}=50 \mathrm{~mm}$.

\subsubsection{Sound absorption coefficients}

The comparison of normal incidence (a) and diffuse field absorption coefficients (b) of the various models are shown in Fig. 6. Fig. 6a suggests that the micro-slit plate filled with porous material considerably improves the normal incidence absorption coefficients (model 1 and 2, model 1 and 4). The double layer micro-perforated plate broadens the absorption band (model 1 and
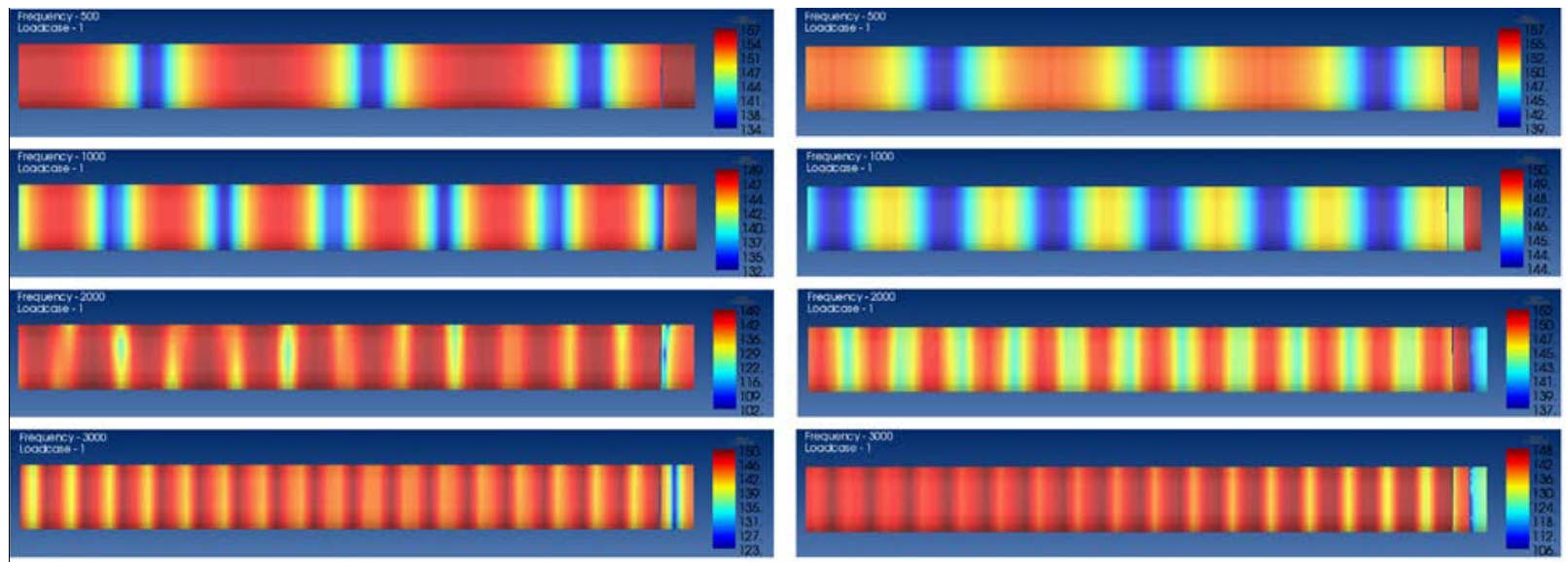

model 1

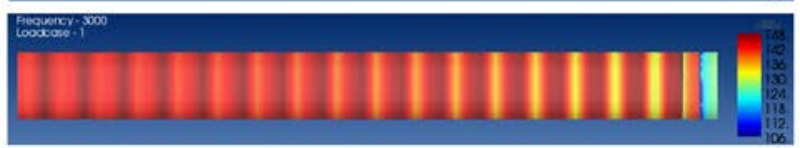

model 3

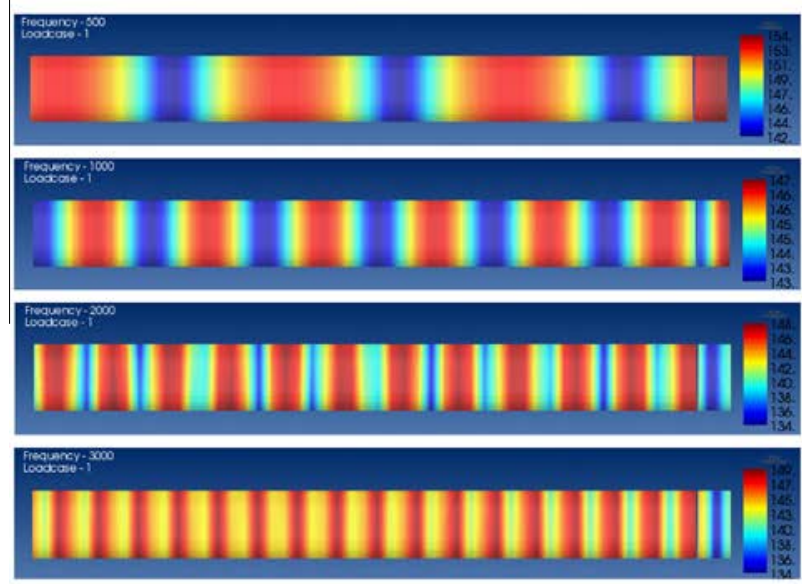

model 2
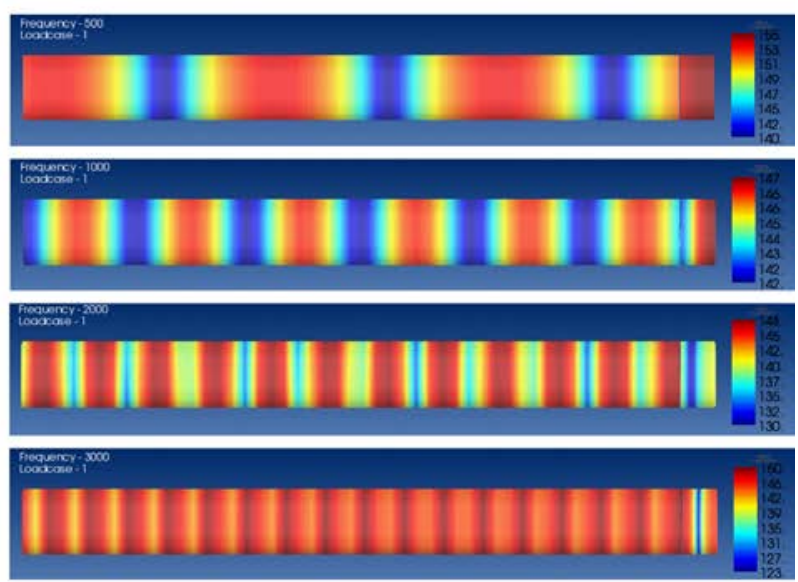

model 4
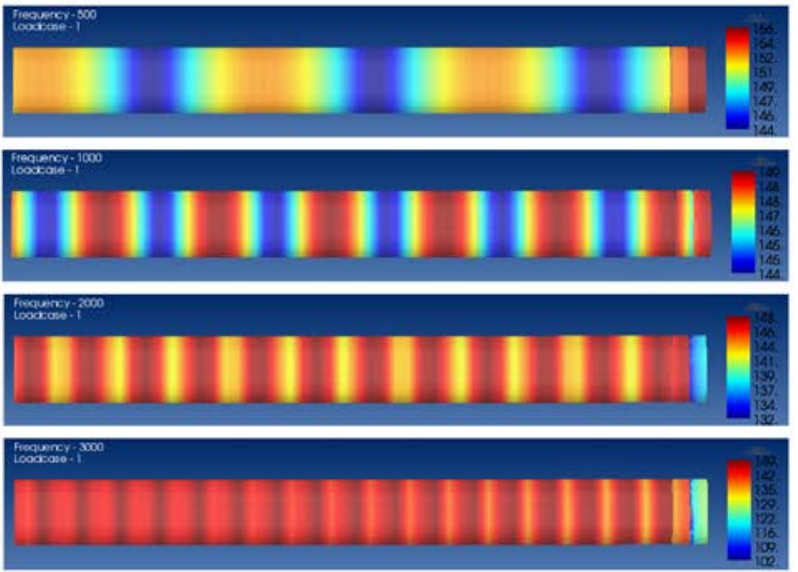

model 5

Fig. 8. Sound pressure (dB) distribution of various models. 
3, model 4 and 5). The bionic model (model 5) has best absorption capacity without increasing the total thickness, and its average normal incidence absorption coefficient reaches 0.85 within the frequency range from $200 \mathrm{~Hz}$ to $2000 \mathrm{~Hz}$. In case of the diffuse field absorption coefficients, Fig. $6 \mathrm{~b}$ indicates that absorption bands of the diffuse field absorption coefficients are much wider than normal incidence. Model 5 shows the best absorption coefficients in both normal incidence and diffuse field.

\subsubsection{Surface sound pressure}

The comparison of surface sound pressures of the various models is shown in Fig. 7. The results suggest that different levels of fluctuations appear in the entire frequency band of the surface sound pressure curves. The plot for model 1 shows significant fluctuations. The change in trends of model 2 and 4, model 3 and 5 are similar. The degree of fluctuation is minimal in frequency range from $650 \mathrm{~Hz}$ to $2000 \mathrm{~Hz}$ for model 3 and 5 and in $650 \mathrm{~Hz}$ to $1300 \mathrm{~Hz}$ for model 2 and 4. Furthermore, on comparison with the normal incident absorption coefficients curves, the frequency bands of minimal fluctuations correspond to the maximum absorption coefficients $(500-2000 \mathrm{~Hz})$.

Fig. 8 presents a visual representation for the influence of different models on sound pressure distribution in the impedance tube. The overall pressure $(\mathrm{dB})$ distributions of impedance tube with various models at $500 \mathrm{~Hz}, 1000 \mathrm{~Hz}, 2000 \mathrm{~Hz}$, and $3000 \mathrm{~Hz}$ are depicted respectively.

\subsection{Optimization of parameters for the bionic model}

The influence of different parameters for each layer of the bionic model on its normal incidence absorption coefficients are investigated and presented as under:

\subsubsection{Angle of incidence}

The angle of incidence is varies from 0 to $\pi / 3$. The influence of incidence angle on absorption coefficients of the bionic model is showed in Fig. 9. The results reveal that the absorption band becomes wider with the increase in the angle of incidence. However, the absorption coefficients for larger incidence angles are found to be smaller in low frequency range $(0-1000 \mathrm{~Hz})$.

\subsubsection{Micro-slit plate}

The parametric study for micro-slit plate includes variation of thickness from $0.5 \mathrm{~mm}$ to $5 \mathrm{~mm}$, diameter from $0.1 \mathrm{~mm}$ to $1 \mathrm{~mm}$ and slotted rate from $1 \%$ to $20 \%$. The influence of above parameters on absorption coefficients of the bionic model are shown in Fig. 10. The results reveal that the thickness and slotted rate of micro-slit plate have notable influence on absorption coefficients. The peak of absorption coefficient moves slightly to low frequencies with increase in the thickness greater than $0.5 \mathrm{~mm}$ (Fig. 10a). However, the absorption band becomes much narrower and the acoustic absorption decreases significantly in the frequency band over $700 \mathrm{~Hz}$. In case of diameter, the absorption coefficients between $600 \mathrm{~Hz}$ and $2000 \mathrm{~Hz}$ increase slightly with increase in diameter above $0.2 \mathrm{~mm}$, but the absorption band becomes a little narrower. The slotted rate shows a completely opposite influence as that of thickness on absorption coefficients of the bionic model.

\subsubsection{Micro-perforated membrane}

The parametric study for micro-perforated membrane includes variation of thickness from $0.05 \mathrm{~mm}$ to $1 \mathrm{~mm}$, diameter from $0.01 \mathrm{~mm}$ to $1 \mathrm{~mm}$ and slotted rate from $0.1 \%$ to $20 \%$. The influence of above parameters on the absorption coefficients of the bionic model are shown in Fig. 11. The results suggest that the influence of membrane thickness is relatively smaller. As the thickness increases, the absorption coefficients at high frequencies have a tin decrease. In case of membrane diameter, the absorption band becomes wider and the trough of wave becomes smaller as the diameter increases from $0.01 \mathrm{~mm}$ to $0.1 \mathrm{~mm}$. However, the peak of absorption coefficient moves to high frequencies and the values at trough of wave becomes larger for diameter more than $0.1 \mathrm{~mm}$. The slotted rates between $0.1 \%$ and $1 \%$ have better absorption capability within the frequency band below $2300 \mathrm{~Hz}$.

\subsubsection{Porous material}

The resistivity of porous material varies from $2000 \mathrm{~Pa} \mathrm{~s} / \mathrm{m}$ to $80,000 \mathrm{~Pa} \mathrm{~s} / \mathrm{m}$. The influence of resistivity for porous material on absorption coefficients of the bionic model is showed in Fig. 12. The results reveal that the absorption band becomes wider with

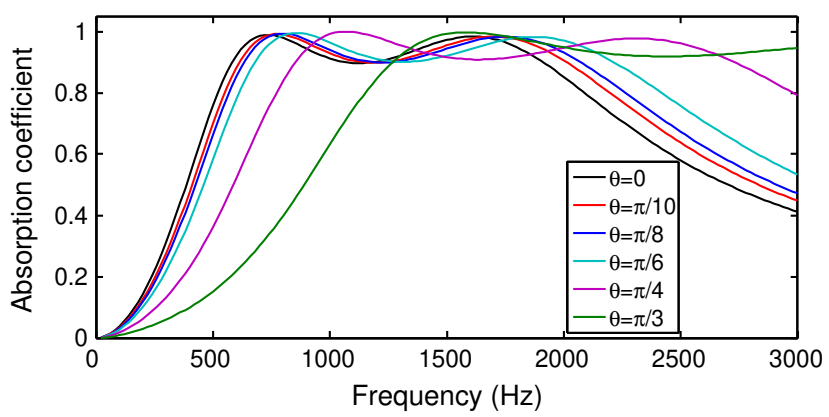

Fig. 9. Influence of incidence angle on absorption coefficients of bionic model
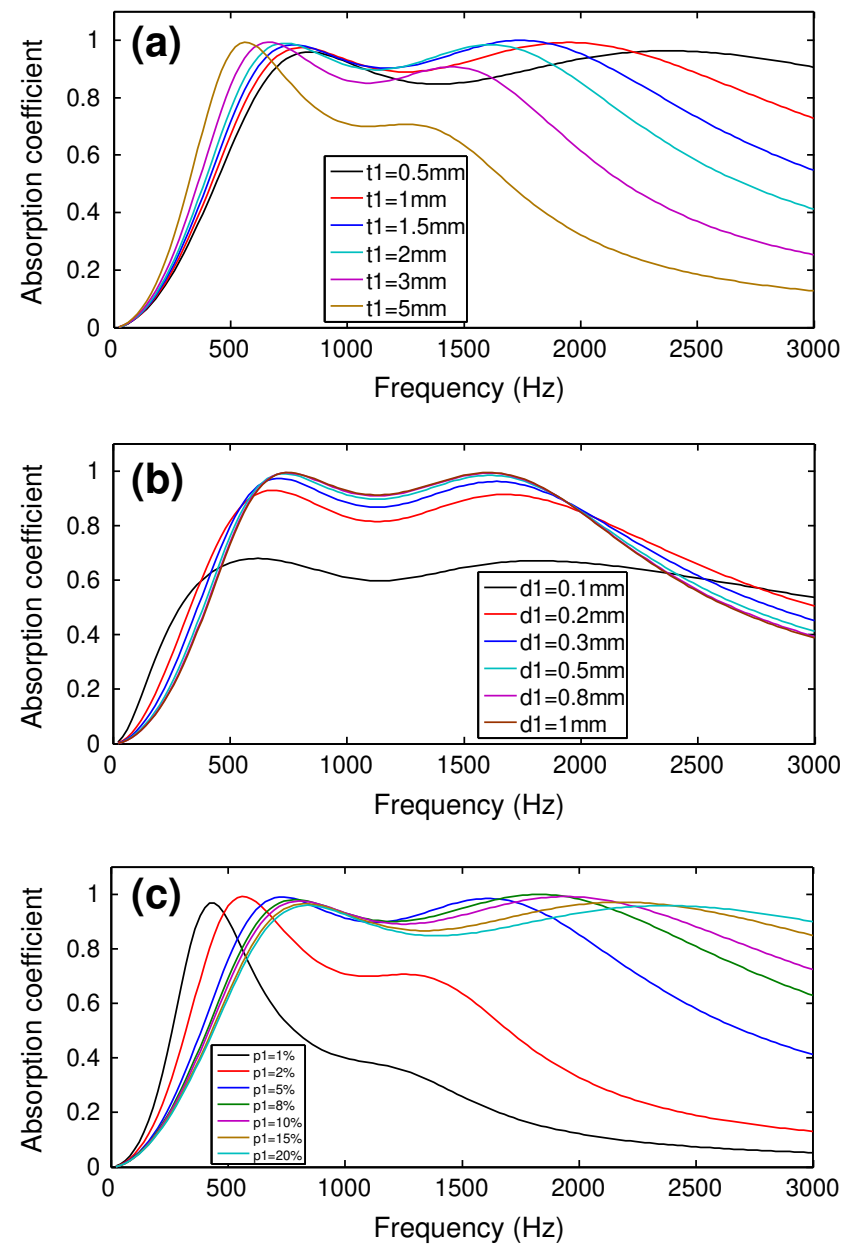

Fig. 10. Influence of (a) thickness, (b) diamater and (c) slotted rate of micro-slit plate on absorption coefficients of bionic model. 

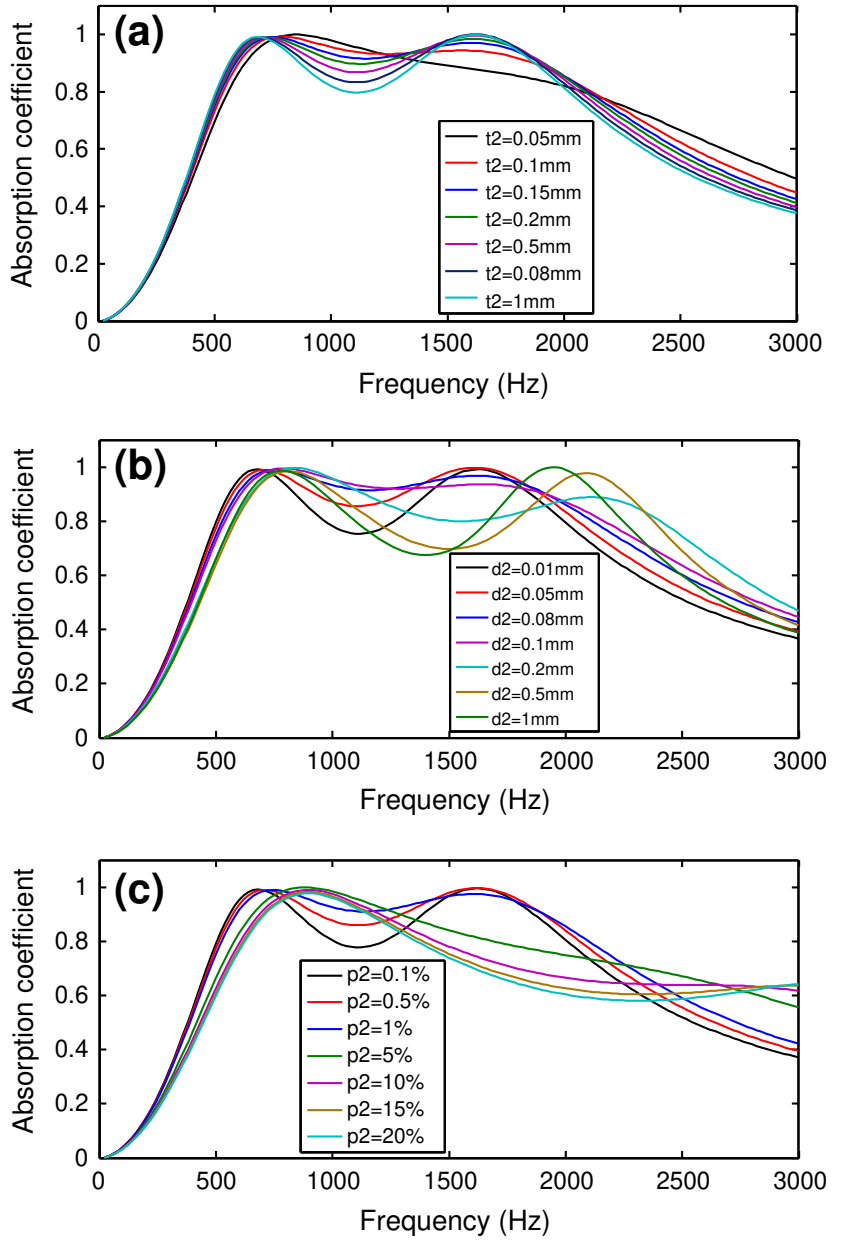

Fig. 11. Influence of (a) thickness, (b) diamater and (c) slotted rate of microperforated membrane on absorption coefficients of bionic model.

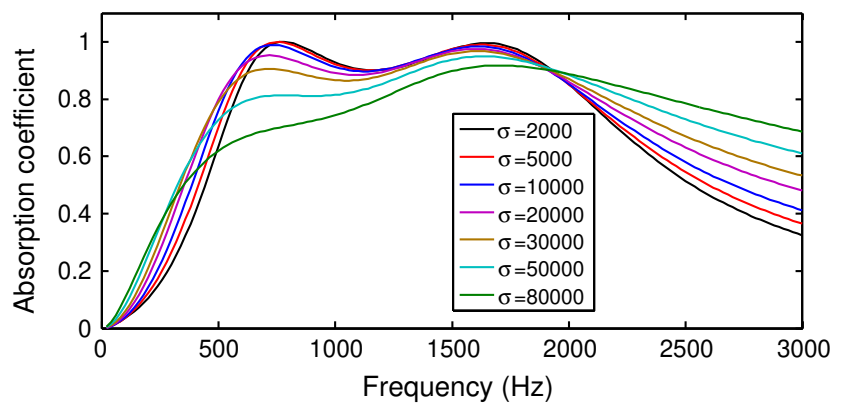

Fig. 12. Influence of resistivity of porous material on absorption coefficients of bionic model.

the increase in resistivity. However, the initial peak decreases significantly at low frequencies.

\subsubsection{Combination of porous material and airspace thickness}

The total thickness of porous material and airspace is constant at $50 \mathrm{~mm}$. The thickness of porous material varies from $10 \mathrm{~mm}$ to $40 \mathrm{~mm}$. The influence of various thickness combinations for porous material and airspace on absorption coefficients is presented in Fig. 13. The results demonstrate that the second peak of absorption coefficient moves to lower frequencies with the increase of porous material thickness. The value at trough of wave increases until the

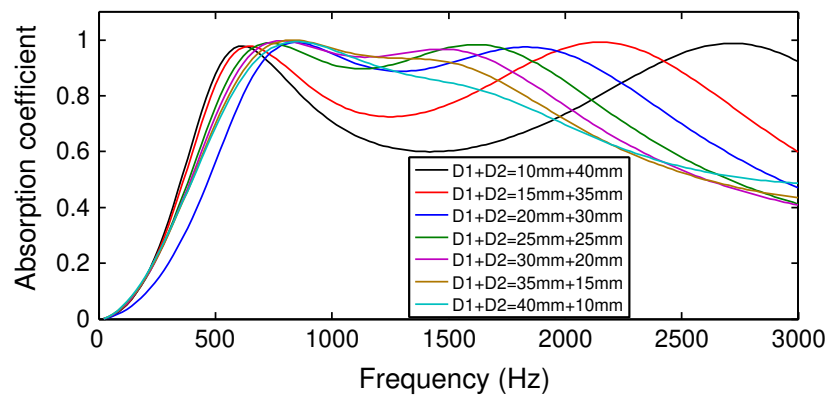

Fig. 13. Influence of combination of porous material and airspace thickness on absorption coefficients of bionic model.

plot completely flattens out. However, the airspace thickness influences the absorption coefficient in the opposite manner.

\section{Conclusions}

In this study, a bionic coupling multi-layer structure is developed based on the biomimetic method. The acoustic performance including impedance, sound pressure and absorption coefficients as well as parametric influence of each layer are investigated by impedance transfer method and finite element method (ACTRAN). The bionic model shows excellent absorption performance. Its average normal incidence absorption coefficient is found to be 0.778 within the frequency range from 0 to $2000 \mathrm{~Hz}$ while 0.85 from $200 \mathrm{~Hz}$ to $2000 \mathrm{~Hz}$. Based on the results and discussion, the optimal parameters are determined as $t_{1}=1 \mathrm{~mm}, d_{1}=0.5 \mathrm{~mm}$, $p_{1}=15 \%, \quad t_{2}=0.1 \mathrm{~mm}, d_{2}=0.05 \mathrm{~mm}, \quad p_{2}=1 \%, D_{1}=20 \mathrm{~mm}$, $\sigma=20,000 \mathrm{~Pa} \mathrm{~s} / \mathrm{m}$, and $D_{2}=30 \mathrm{~mm}$. The significant improvement of absorption coefficients at low frequencies can be attributed to the Helmholtz effects of the micro-silt plate and flexible microperforated membrane, and the combination with porous materials, which leads to even better absorption performance in broadband. The study emphasizes that further investigations on the bionic coupling multi-layer structure can provide better absorbing system for practical applications.

\section{Acknowledgments}

All support is greatly acknowledged and appreciated, especially the constructive discussion and criticism from colleagues. Thanks are due to the Joint Funds of the National Natural Science Foundation of China (Grant No. U1134109), the Specialized Research Fund for the Doctoral Program of Higher Education of China (Grant No. 20110061120048), and the projects of National Natural Science Foundation of China (Grant Nos. 31071928, 51106062 and 51206058 ), for allowing to undertake the project and the financial support extended.

\section{References}

[1] Xue CY, Chen S, Zhang WD, Zhang BZ, Zhang G], Qiao H. Design, fabrication, and preliminary characterization of a novel MEMs bionic vector hydrophone. Microelectron J 2007;38:1021-6.

[2] Han ZW, Niu SC, Shang CH, Liu ZN, Ren LQ. Light trapping structures in wing scales of butterfly Trogonoptera brookiana. Nanoscale 2012;4:2879-83.

[3] Ren LQ, Tong J, Li JQ Chen BC. Swsoil and water: soil adhesion and biomimetics of soil-engaging components: a review. J Agric Eng Res 2001;79:239-63.

[4] Sun TL, Feng L, Gao XF, Jiang L. Bioinspired surfaces with special wettability. Acc Chem Res 2005;38:644-52.

[5] Feng L, Li HS, Li YS, Li HJ, Zhang LJ, Zhai J. Superhydrophobic surfaces: from natural to artificial. Adv Mater 2002:14:1857-60.

[6] Graham RR. The silent flight of owls. J Roy Aeronaut Soc 1934;38:837-43.

[7] Kroeger RA, Grushka HD, Helvey TC. Low speed aero-dynamics for ultra-quiet flight. Technical report AFFDL-TR-71-75. Air Force Flight Dynamics Lab, Wright-Patterson Air Force Base, Ohio, USA; 1971. 
[8] Lilley GM. A study of the silent flight of the owl. AIAA Paper; 1998. p. 2004186.

[9] Lilley GM. A quest for quiet commercial passenger transport aircraft for takeoff and landing. AIAA Paper; 2004. p. 2922.

[10] Sun SM, Ren LQ, Xun CY. Research on coupling sound absorption property of owl skin and feather. Noise Vib Contr 2008;6:119-23 [in Chinese].

[11] Liu TS, Kuykendoll K, Rhew R, Jones S. Avian wings. AIAA Paper; 2004. p. AIAA2004-2186.

[12] Ahuja KK, Stevens JC. Recent advances in active noise control. In: Proceedings of the 13th AIAA, Aeroacoustics Conference, Tallahassee, FL; 1990.

[13] Miccoli G, Concilio A. Recent advances in noise and vibration active control by means of piezoelectric transducers. In: Proceedings of the 3rd international congress on air- and structure-borne sound and vibration, Montreal. Canada; 1994. p. $1377-84$.

[14] Ross C. Current developments and future trends in active noise control. Noise Vib Contr Worldwide 1989:171-3.

[15] Tichy J. Current and future issues of active noise control. J Acoust Soc Jpn (E) $1991 ; 12: 255-62$.

[16] Hirsch SM, Jayachandran V, Sun JQ. Structural-acoustic control for quieter aircraft interior-smart trim technology. Compos Struct 1998;42:189-202.

[17] Davern WA. Perforated facings backed with porous materials as sound absorbers - an experimental study. Appl Acoust 1977;10:85-112.

[18] Dunnand IP, Davern WA. Calculation of acoustic impedance of multilayer absorbers. Appl Acoust 1986;19:321-34.

[19] Jinkyo L, George W, Swenson J. Compact sound absorbers for low frequencies. Noise Contr l Eng J 1992:38:109-17.

[20] Chen WH, Lee FC, Chiang DM. On the acoustic absorption of porous materials with different surface shapes and perforated plates. J Sound Vib 2000;237:337-55

[21] Buitrago BL, Santiuste C, Sánchez-Sáez S, et al. Modelling of composite sandwich structures with honeycomb core subjected to high-velocity impact. Compos Struct 2010;92:2090-6.
[22] Koutsawa Y, Azoti WL, Belouettar S, et al. Loss behavior of viscoelastic sandwich structures: a statistical-continuum multi-scale approach. Compos Struct 2012;94:1391-7.

[23] Wang SC, Deng ZX, Shen WD. Sound transmission loss characteristics of unbounded orthotropic sandwich panels in bending vibration considering transverse shear deformation. Compos Struct 2010;92:2885-9.

[24] Larbi W, Deü JF, Ohayon R. Finite element formulation of smart piezoelectric composite plates coupled with acoustic fluid. Compos Struct 2012:94:501-9.

[25] Lin L, Wang ZM, Jiang ZX. Effect of sound-absorbing material on a microperforated absorbing construction. ACTA Acoust 2010;4:385-92.

[26] Lee DH, Kwon YP. Estimation of the absorption performance of multiple layer perforated panel systems by transfer matrix method. I Sound Vib 2004;278:847-60.

[27] Lee FC, Chen WH. Acoustic transmission analysis of multi-layer absorbers. Sound Vib 2001:248:621-34.

[28] Zhao XD, Hu P, Sun P. The comparative analyses of the calculation methods for absorptivity of multilayer micro-perforated panel absorbers. Appl Acoust 2012;3:6.

[29] Maa DY. Theory of microslit absorbers. Acta Acust 2000;25:481-5.

[30] Miki Y. Acoustical properties of porous materials - modifications of DelanyBazley models. J Acoust Soc Jpn (E) 1990;11:19-24.

[31] Kang J, Fuchs HV. Predicting the absorption of open weave textiles and microperforated membranes backed by an air space. J Sound Vib 1999;220:905-20.

[32] Allard JF, Atalla N. Propagation of sound in porous media: modelling sound absorbing materials. Elsevier; 2009.

[33] ISO 10534-2. Acoustics-determination of sound absorption coefficient and impedance in impedances tubes - Part 2: Transfer-function method International Organization for Standardization; 1998 